\title{
Novos ambientes educacionais: desafios do uso das tecnologias educacionais inovadoras no contexto escolar
}

\author{
Puntel Diane Roehrs', Liziany Muller², Aline Pereira de Arruda Rech ${ }^{3}$ \\ I, 2, 3 Universidade Federal de Santa Maria, Santa Maria
}

\section{Resumo}

Apontar os principais desafios da presença das tecnologias no ambiente escolar é o objetivo deste artigo. A metodologia empregada foi pautada em uma pesquisa exploratória com abordagem qualitativa num paradigma construtivista. A primeira ação desenvolvida para instigar a reflexão dos professores e dos alunos foi assistir ao vídeo: Você não pode ser meu professor, disponível em: http://www.youtube/ watch?v=R1KalH1YbM. E como instrumento de coleta de dados foi adotado um questionário com questões abertas e fechadas para os alunos e professores de $5^{\mathrm{a}}$ a $8^{\mathrm{a}}$ série da Escola Estadual de Ensino Médio Tomas Garcia da Costa no município de Lagoão/RS. Os resultados obtidos indicam que a maioria dos alunos tem acesso às tecnologias. Eles citaram o laboratório de informática, como o recurso que mais motiva, desperta a atenção e auxilia a compreensão dos conteúdos no ambiente escolar. Todos os professores concordaram que a sala de aula apenas com quadro e giz não pode ser o único mediador do processo de ensino-aprendizagem dos alunos. Eles também, afirmaram utilizar o computador/internet como forma de lazer, mas também, como ferramenta para busca de recursos educacionais (vídeos, figuras, músicas, artigos, mapas, etc) visando melhorar sua prática pedagógica.

Palavras-chave: TIC- Educação-Motivação- Aprendizagem

\begin{abstract}
Identify the main challenges in the presence of technology in the school environment is the main objective of this article. The methodology was based on an exploratory qualitative approach with a constructivist paradigm. The first action designed to instigate reflection of teachers and students was watching the video: You cannot be my teacher, available at: http://www.youtube/watch?v=R1KalH1YbM. As an instrument for data collection, it was used a questionnaire with open and closed questions for students and teachers from 5th to 8th grade of State High School Tomas Garcia da Costa in Lagoão / RS. The results indicate that most students have access to technology. They cited the computer lab, as the feature that most motivates, awakens the attention and helps the understanding of the contents in the school environment. All teachers agreed that classroom with blackboard and chalk just cannot be the only mediator of the process of teaching and student learning. They also said that they use the computer / internet as a form of recreation, but also as a tool for finding educational resources (videos, pictures, songs, articles, maps, etc.) to improve their teaching.
\end{abstract}

Keywords: ICT-Education, Motivationand Learning 


\section{INTRODUÇÂO}

Atualmente a tecnologia está presente em todos os setores da sociedade e é um componente social importante na vida moderna. O acesso à mídia eletrônica, ao vídeo, ao computador, às redes está sendo uma condição básica da habitação do cidadão ao diálogo social, afetivo, político, profissional e sua inclusão na sociedade.

Neste contexto,

"A implementação das Tecnologias de Informação e Comunicação nas escolas representa um dos maiores desafios de inovação pedagógica e tecnológica enfrentado pelos sistemas de educação em todo o mundo (ALMEIDA, 2003).

As TIC em Educação são recursos/ferramentas imprescindíveis na vida do professor, desde que sejam exploradas de forma criativa e interativa, tornando o aluno construtor do seu conhecimento (DEDALD, 2007). Desta forma, o professor passa a ser o mediador, o facilitador, o orientador desta informação, onde necessita modificar sua prática pedagógica, bem como, o paradigma em que se apoiava até o momento para ousar e aventurar-se nas TIC (DEDALD, 2007).

De acordo Castro com et al. (2011) "a escola deve ser mais ousada, inovadora e prazerosa, para que o aluno construa seus saberes, com alegria e prazer, possibilitando a criatividade e o pensar criticamente". As aulas devem transpor os limites do ensino tradicional, das aulas condutivistas e livrescas e permitir aos alunos vivenciar os conteúdos além das salas de aula.

Castro et al (2011) destacam as potencialidades das TIC, dentre as quais se evidenciam a forma de ensino que é ativa, onde o professor ocupa um lugar intermediário entre a informação e os alunos, sendo um mediador que aviva a capacidade criadora, a autonomia e o pensamento crítico dos alunos. Possibilita também a diversificação das metodologias de ensino-aprendizagem, aumentando a motivação de alunos e professores, além de mostrar-se uma ferramenta capaz de promover a interdisciplinaridade.

Introduzir as TIC nas aulas é uma tarefa desafiadora. Deste modo, este projeto de pesquisa visa, conhecer o perfil dos professores, a opinião deles sobre as inovações tecnológicas e as possibilidades do uso das tecnologias em sala de aula. Do mesmo modo, pretendem-se saber quais são os conhecimentos dos alunos sobre as inovações tecnológicas, o que eles pensam do uso do computador e da internet em sala de aula e a sua ideia sobre os professores e as técnicas utilizadas por eles em sala de aula.

Este estudo tem por objetivo investigar a relação dos professores e alunos com a utilização das tecnologias da informação em sala de aula, bem como reconhecer e afirmar a importância dos recursos tecnológicos no processo ensino - aprendizagem.

\section{METODOLOGIA}

A metodologia utilizada foi de uma pesquisa exploratória com abordagem qualitativa.

O trabalho foi desenvolvido na Escola Estadual de Ensino Médio Tomas Garcia da Costa, localizada no centro da cidade de Lagoão, RS. Esta instituição de ensino tem como objetivo proporcionar aos estudantes situações que contribuam para o desenvolvimento social, cognitivo, afetivo, psicomotor, atenção e o raciocínio lógico, dentro de uma pedagogia lúdica e de livre expressão, levando-as à estruturação das noções básicas na formação da sua personalidade e de caráter, capazes de auxiliá-las na leitura e na escrita do mundo.

Como instrumento de coleta de dados será utilizado um questionário realizado a partir de um vídeo do youtube: http://www.youtube.com/watch?v=R1KaIH1_YbM;" Você não pode ser um professor", (figura 1) o qual leva em consideração o uso e o conhecimento das tecnologias da informação pelos professores e alunos e o interesse dos mesmos em utilizá-los como mecanismo de aprendizagem. Assim, nossa primeira ação é investigar a reflexão dos professores e alunos após assistirem o vídeo.

Para a pesquisa, foram entrevistados 40 alunos que estudam de $5^{\mathrm{a}}$ a $8^{\mathrm{a}}$ série, e seus respectivos professores de todas as disciplinas do currículo, totalizando nove educadores entrevistados.

Como instrumentos de coleta de dados foram adotados dois questionários com 21 questões abertas e fechadas, um para professores e outro questionário para os estudantes, quadro 1 e 2 .

A aplicação do questionário ocorreu no mês de setembro de 2012 e levou em consideração os seguintes aspectos: recursos tecnológicos utilizados, interesse dos estudantes, disciplina, motivação, 


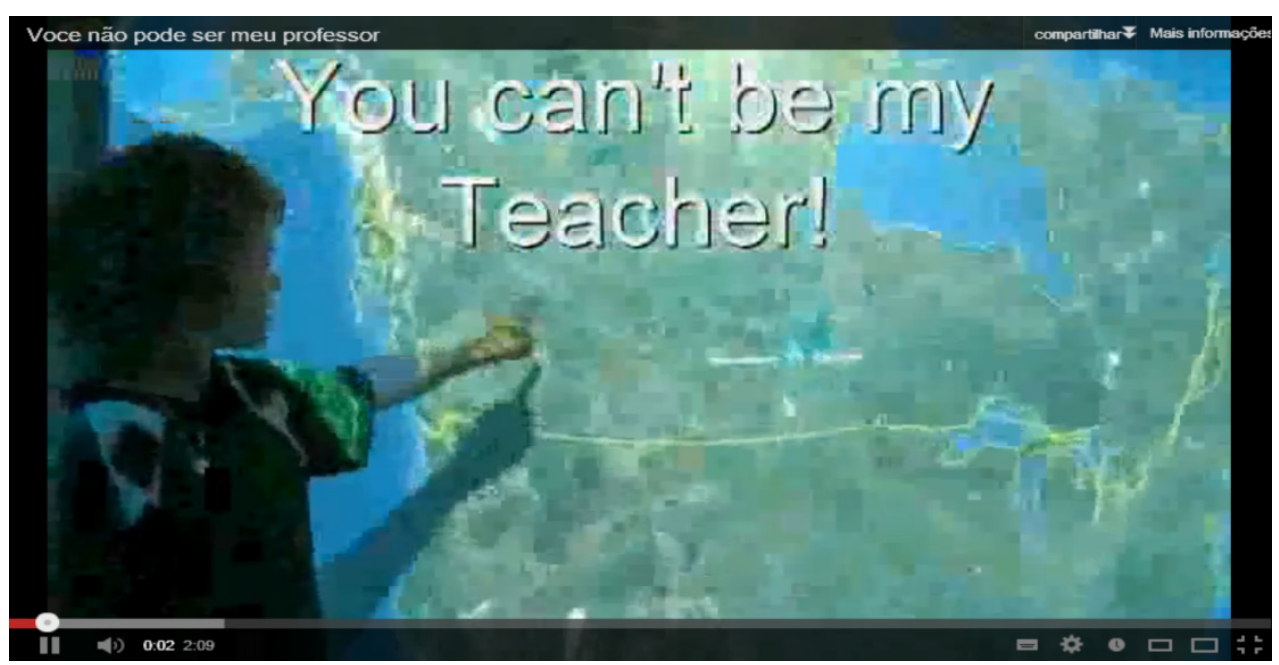

Figura1: Imagem ilustrativa do vídeo assistido pelos professores e alunos da Escola Estadual de Ensino Médio Tomas Garcia da Costa Fonte: http://www.youtube/watch?v=R1KalH1 YbM.

participação, aprendizagem, dificuldade em trabalhar o conteúdo, resultados da utilização dos recursos tecnológicos para o processo ensino-aprendizagem e indicação de recursos tecnológicos que gostaria que fossem utilizados na prática pedagógica.

Quadro1- Questionário aplicado aos professores de $5^{\mathrm{a}}$ a $8^{\mathrm{a}}$ série do Ensino Fundamental da Escola Estadual de Ensino Médio Tomas Garcia da Costa.

\begin{tabular}{|c|c|}
\hline \multicolumn{2}{|c|}{ Questões } \\
\hline \multicolumn{2}{|c|}{ 1. Qual seu nível de formação? } \\
\hline ( )Mag & ( )Curso Superior ( )Especialização ( ) Mestrado ( ) doutorado \\
\hline \multicolumn{2}{|c|}{$\begin{array}{l}\text { 2. Em sua opinião a sala de aula é o único lugar em que os alunos têm um } \\
\text { aprendizado significativo? Justifique? }\end{array}$} \\
\hline \multicolumn{2}{|c|}{$\begin{array}{l}\text { 3. Em sua opinião, uma sala onde os alunos ficam todos sentados atrás de } \\
\text { uma classe, possui um quadro negro e livros é o essencial para transmitir conhe } \\
\text { cimento? Por quê? }\end{array}$} \\
\hline \multicolumn{2}{|c|}{$\begin{array}{l}\text { 4. Você sabe utilizar o computador e a internet? Você as utiliza para o lazes } \\
\text { ou como mecanismo de aprendizagem? }\end{array}$} \\
\hline \multicolumn{2}{|c|}{ 5. Você está conectado nas redes sociais, facebook, Orkut, twitter? Por quê? } \\
\hline \multicolumn{2}{|c|}{$\begin{array}{l}\text { 6. Neste ambiente de inovações tecnológicas você pensa que todo profes- } \\
\text { sor deve estar conectado ao mundo virtual? }\end{array}$} \\
\hline ( )Sim & ( )Não \\
\hline \multicolumn{2}{|c|}{$\begin{array}{l}\text { 7. Alguns professores ainda não possuem conhecimento com computador } \\
\text { e internet. Em sua opinião é possível eles transmitirem um conhecimento signifi- } \\
\text { cativo para seus alunos sem utilizar as tecnologias da informação? }\end{array}$} \\
\hline ( ) $\operatorname{Sim}$ & Não \\
\hline
\end{tabular}


8. Você como professor concorda como exposto no vídeo?

9. Em sala de aula quais recursos e atividades utiliza para tornar as aulas mais criativas facilitando assim a aprendizagem dos alunos? Justifique

10. Você já realizou algum curso de capacitação sobre o uso da tecnologia informação e comunicação como mediador no processo de ensino-aprendizagem?( ) não ( ) sim

11. Você utiliza a internet para fazer pesquisas para preparar suas aulas?

( ) não ( ) sim

12. Em sua opinião, qual a finalidade do uso das tecnologias de informação e comunicação no ensino fundamental.

Quadro2- Questionário aplicado aos alunos de $5^{\mathrm{a}}$ a $8^{\mathrm{a}}$ série do Ensino Fundamental da Escola Estadual de Ensino Médio Tomas Garcia da Costa.

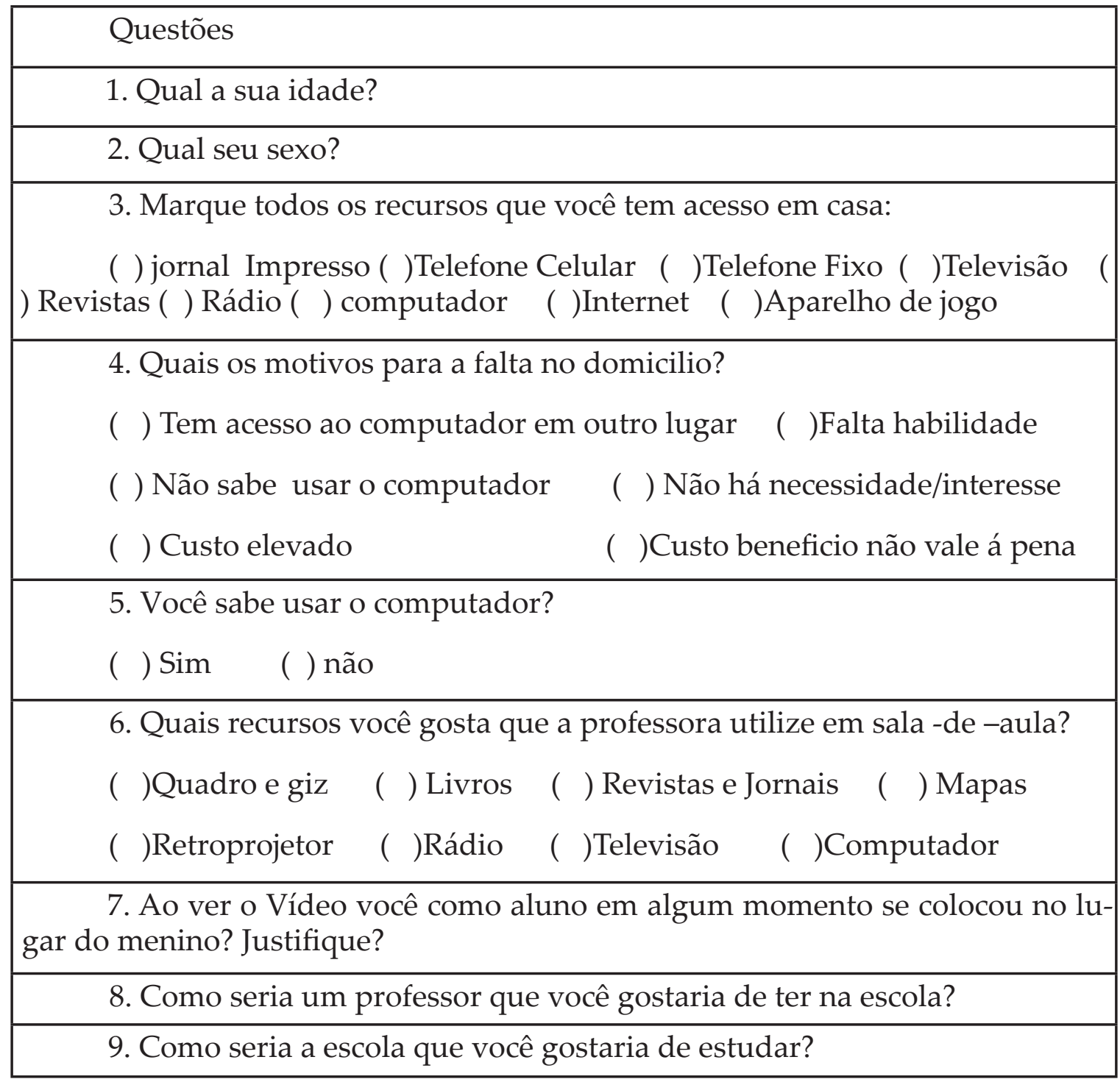




\section{RESULTADOS E DISCUSSÕES}

A partir dos resultados obtidos dos questionários respondidos, podemos entender suas realidades vivenciadas, apontar as principais dificuldades enfrentadas para ter acesso ao TIC, que na atualidade representa uma ferramenta de extrema importância para ampliar e aprimorar o conhecimento do professor e também obter a inclusão do aluno neste meio.

Para melhor entender esta realidade, foi desenvolvido questionários distintos para alunos e professores, onde em um primeiro momento será apresentado e discutido os dados obtidos pela entrevista realizada com os alunos e a seguir serão exibidos os dados dos professores entrevistados.

Conhecer o perfil e auxiliar a inclusão digital dos alunos das escolas públicas da zona rural é fundamental para o aprimoramento do processo de ensino-aprendizagem dos estudantes, uma vez que, a educação é um dos caminhos para desenvolvimento dessas comunidades. Os alunos entrevistados, na Escola Tomas Garcia da Costa possuem idade entre 10 a 16 anos, ficando na faixa etária ideal para as respectivas séries que estão cursando, sendo a minoria do sexo masculino (40\%).

Os resultados obtidos na questão 3 (quadro 2) do questionário dos alunos foram muito relevantes. Foi possível constatar que o maior percentual de acesso a estes recursos está representado pela aquisição de telefone celular (19\%), televisão (19\%) e rádio (18\%). Isto de deve ao fato de estes produtos terem um valor de mercado facilitado e expansão do sinal de telefonia o que não ocorre com o telefone fixo. Com relação aos que apresentam menor acesso aos recursos, estão representados pelo telefone fixo (4\%), jornal impresso (6\%), internet (7\%), revistas (8\%), aparelho de jogo (8\%) e computador $(11 \%)$. Estes dados foram muito significantes e demonstram um percentual muito expressivo de entrevistados que não possuem acesso em casa a estes recursos. Isto se deve ao fato de muitos morarem em lugares de difícil acesso, impossibilitando a chegada destas tecnologias e também pelo custo mensal que representa na renda destas famílias, impossibilitando sua aquisição. Neste contexto, conforme Debald (2007):

Para alcançar uma comunicação mais significativa na educação, tem-se como possibilidade a utilização das ferramentas de comunicação e informação como chat, e-mail, fórum, telefone, pois estas ferramentas podem estar disponíveis num ambiente de aprendizagem.

Para seguimento de análise da pesquisa, também foi aplicado o questionário perguntando aos entrevistados quais os motivos para a falta de computador a domicilio (Questão 4-quadro 2). Os resultados obtidos foram muito expressivos, representando um percentual de $43 \%$ dos entrevistados que não possuem computador em sua residência e apontam a principal causa o elevado custo (43\%) que este investimento representa. Com isto podemos verificar que grande parte dos entrevistados dispõe de um poder aquisitivo reduzido, o que os impossibilita de ter acesso a esta ferramenta que atualmente é um mecanismo fundamental como fonte de pesquisa, aprendizado e inclusão a tecnologia da informação. Por outro lado, temos uma percentual de $25 \%$ que não possuem computador, mas tem acesso ao computador em outro lugar.

Também podemos perceber que existe um pequeno percentual (5\%) que ainda desconhece os recursos que esta tecnologia pode proporcionar e apontam que o custo beneficio não vale à pena, sendo possível constatar que esta pequena minoria precisar ser inserida neste contexto e o professor é alvo desta competência de inclusão.

Para obtenção de um percentual do número de alunos que sabem utilizar o computador e internet, também foi incluído no questionário da pesquisa a pergunta (Questão 5-quadro 2).

Os dados obtidos foram muito significados e de certa forma otimista, pois foi possível obter um percentual de $90 \%$ de alunos que sabem manusear um computador. Isto demonstra, que mesmo a grande maioria não dispondo de computador em casa, de alguma forma este alunos buscam este conhecimento e obtiveram este aprendizado. Os entrevistados também afirmaram que os endereços eletrônicos que mais acessam e aplicativos que mais utilizam são: jogos, escrever, desenhar, desenvolver trabalhos pedidos pelos professores, assistir vídeos, pesquisas, para se comunicar nas redes sociais tais como MSN, twitter, Orkut e facebook para fazer cursos, ler notícias, escutar músicas, entre outros. O percentual representado pelos $10 \%$, por algum motivo ainda não sabe usar o computador, sendo possível constatar que através da escola que disponibiliza deste recurso, este aluno devera ser incluído 
e obter este aprendizado assim como os demais. Desta forma segundo Almeida et al, (2003):

O contacto regular e orientado do aluno com o computador em situação de ensino aprendizagem contribui positivamente para o desenvolvimento cognitivo e intelectual, em especial o raciocínio lógico e formal, a capacidade de pensar com rigor e sistematicamente, a habilidade de inventar ou encontrar soluções para problemas. Desta forma, é dada oportunidade ao aluno de ter um papel ativo na construção da sua aprendizagem. Mesmo os maiores críticos do uso do computador na educação não ousam negar esse fato.

Para melhor entender os recursos que os alunos apontam mais gostar que o professor utilize em sala de aula, foi realizado o levantamento desde dados (Questão 6-quadro 2).

A partir dos dados obtidos, é possível apontar que uma margem de 14\% dos alunos preferem a utilização do quadro negro e do giz, $9 \%$ de livros e também o mesmo percentual de alunos preferem a utilização de revistas, jornais e mapas. Por outro lado, uma pequena minoria (6\%) prefere ainda a utilização do retroprojetor, mas alguns alunos (15\% da turma) preferem rádio e $14 \%$ televisão, mas a grande maioria $24 \%$ dos alunos prefere que o recurso computacional seja o mecanismo de ensino mais utilizado pelo professor. Com isto é possível mensurar o grande avanço que esta tecnologia representa, pois os alunos vem o computador e a internet como uma ferramenta completa em todos os aspectos educacionais e de lazer.

Com base nos dados Concorda-se com Lévy (1993), quando aponta três categorias de conhecimento existentes nas sociedades - a oral, a escrita e a digital. O autor conclui afirmando que:

Estilo digital engendra, obrigatoriamente, não apenas o uso de novos equipamentos para a produção e a apreensão de conhecimentos, mas também novos comportamentos de aprendizagem, novas racionalidades, novos estímulos perceptivos. Seu rápido alastramento e sua rápida multiplicação obrigam-nos a não mais ignorar sua presença e sua importância.

Na próxima questão da entrevista (Questão 7-quadro 2) foi indagado se ao ver o vídeo, como aluno, em algum momento se colocou no lugar do menino.

As respostas dos alunos estão representadas por um percentual de $41 \%$ dos entrevistados que não se colocaram no lugar do aluno do vídeo, devido ao fato de acreditarem que o professor não precisa usar computador ou internet. Em contra partida, foi obtido um percentual de $32 \%$ de alunos que se colocou no lugar do aluno do vídeo, acreditando que esta ferramenta é um instrumento de ajuda no aprendizado e que deverá ser utilizado pelo professor, porém apontam a falta de domínio na utilização do computador e internet e $27 \%$ dos alunos não responderam esta questão.

Através dos dados obtidos, foi possível verificar que existe conflito de opiniões, devendo este assunto ser mais abordado pelo professor e este estar mais preparado de forma a acompanhar a evolução tecnológica, pois é possível constatar que ainda existe uma dificuldade do aluno em entender a forma do uso correto desta tecnologia, o que ela proporciona e como poderá contribuir no aprendizado.

Desta forma, de acordo com Debald (2007) para usar adequadamente as TIC em sala de aula torna-se necessário não só um processo de integração e domínio dos meios tecnológicos de computação, mas também um conhecimento de como estes meios podem ser utilizados para potencializar o processo de ensino. Este processo é lento e gradual. Conforme Kenski (2003), a adaptação ao novo ambiente tecnológico, com a exploração de suas potencialidades para a educação, é obtida após três meses de experiências.

Também foi perguntado aos alunos entrevistados sobre como seria um professor que gostaria de ter em sua escola e como seria a escola que gostaria de estudar (Questão 8-quadro-2). Através das respostas foi possível perceber duas linhas de pensamento entre os alunos entrevistados. Uma linha gostaria de ter professores que não falassem mal dos alunos, que os levassem para a sala de computação, não dessem trabalhos, deixassem livre para fazer o que quisessem.

Outros afirmaram que gostariam de ter um professor que tivesse o controle sobre a aula e que os entendessem melhor, que dessem atenção a todos sem distinção, sem demonstrar preconceito, que usassem mais a tecnologia através de pesquisas na internet, que fizessem trabalhos em grupo, enfim, um professor que conquiste o aluno através de seu carisma, simpatia, educação, respeito mútuo, 
demonstrando sua responsabilidade e exigindo a contrapartida do aluno.

Sobre a escola que gostariam de estudar (Questão 9-quadro 2) eles afirmaram que gostariam que tivesse bastante espaço, que fosse bonita e legal onde todos se tratassem com respeito, com acesso a tecnologia, que tivesse uniforme, que os alunos cuidassem melhor da limpeza, pois está poluída de lixos, que oferecesse métodos modernos de estudos para melhorar o ensino-aprendizagem.

Neste segundo momento, serão apresentados os dados obtidos a partir das respostas dos professores entrevistados.

Na pergunta número 1 (quadro-1) do questionário foi possível observar que a maioria dos professores (47\%) possuem graduação e grande parte dos mesmos pós-graduação (33\%) e ainda há 20\% que possuem magistério como sua formação. Ficando nítido que estes estão qualificados e levando a sério a importância que uma boa formação tem. Para Kenski (2003):

A formação do professor para atender às novas exigências originárias da cultura informática na educação precisa refletir esses mesmos aspectos [...] a atualização permanente é condição fundamental para o bom exercício da profissão docente.

Os entrevistados foram indagados (questão 2-quadro 1) quanto a sua opinião sobre a sala de aula, se a mesma é o único lugar em que os alunos têm um aprendizado significativo, onde a resposta foi unânime (100\%), todos responderam que a sala de aula não é o único lugar para um aprendizado significativo, e que qualquer ambiente tais como em casa, nas igrejas, no CTG, na sociedade, ou seja, qualquer lugar pode ser lugar para aprender. Todo ambiente e ferramentas tecnológicas podem ser propícios para o aprendizado basta que o professor saiba explorá-lo de maneira a contribuir para o processo de ensino e de aprendizagem.

Nesse sentido, conforme Barros (2009), a tecnologia é um instrumento capaz de aumentar a motivação dos estudantes, se sua utilização estiver inserida em um ambiente de aprendizagem desafiador, mas, não é por si só um elemento motivador se a proposta de trabalho não for interessante, pois os estudantes rapidamente perdem a motivação.

Os professores também foram indagados (questão 3-quadro1) ) sobre sua opinião quanto a uma sala de aula onde os alunos ficam todos sentados atrás de uma classe, possui um quadro negro e livros é o essencial para transmitir conhecimento e por que. A resposta foi unânime (100\%) que este espaço não é o essencial, pois com toda a tecnologia disponível é preciso inovar, mostrar novas formas de aprender, ser criativo para tornar as aulas atrativas utilizando outros recursos além dos disponíveis dentro de uma sala de aula normal.

Neste sentido, para Delbad (2007), é necessário que o professor diversifique sua prática pedagógica, incentive e estimule aprendizagem, oportunizando que o aluno conheça e valorize o que está sendo estudado, de forma que deve usar a criatividade em sala de aula para estabelecer um diálogo constante com a realidade para ter uma visão ampliada do que está acontecendo fora da sala de aula.

Os entrevistados foram questionados (Questão 4 - quadro1) também se sabem utilizar o computador e a internet e se as utiliza para o lazer ou mecanismo de aprendizagem. Todos os investigados afirmaram que sabem utilizar e que usam os mesmos para o lazer e também para pesquisas, e utilizam como meio de ensino-aprendizagem.

Conforme MORAN (2000).

O educador autêntico é humilde e confiante, mostra o que sabe, porém está sempre atento ao novo, ensina aprendendo a valorizar a diferença, a improvisar. Aprender por sua vez é passar da incerteza a uma certeza provisória, pois dará lugar as novas descobertas, não há estagnação no sistema de aprendizagem e descobertas.

Outro questionamento (Questão 5-quadro 1) foi se os docentes estão conectados as redes sociais tais como facebook, Orkut, twitter e por quê. Todos eles afirmaram que utilizam alguma das redes sociais indicadas e além desses indicaram também o MSN. Justificam que utilizam essas ferramentas para se comunicar com pessoas que fazem ou fizeram parte de suas vidas, ou apenas meros conhecidos. Também afirmaram que as mesmas podem ser utilizadas como ferramenta de trabalho e pesquisa, facilitando a comunicação e a mediação do conhecimento. 
Contextualizando com um ambiente de inovações tecnológicas em que vivemos, foi perguntado ao entrevistado (questão 6-quadro1) se ele pensa que todo professor deve estar conectado ao mundo virtual e por quê. A resposta foi positiva por todos os professores, justificando a necessidade do mesmo, assim como qualquer outro profissional adaptar-se a evolução do crescente desenvolvimento tecnológico que é uma realidade presente em nosso dia-a-dia.

No questionário (questão 7-quadro 1) havia uma afirmação de que alguns professores ainda não possuem conhecimento sobre computador e internet, e em seguida perguntava se na opinião do entrevistado é possível compartilhar conhecimento significativo para seus alunos sem utilizar as tecnologias da informação. Nesse questionamento, todos os docentes afirmaram que o computador é fundamental para auxiliar no compartilhamento de conhecimentos significativos.

$\mathrm{Na}$ questão seguinte (Questão 8-quadro-1) perguntou-se a opinião do professor sobre o vídeo, se concorda ou não com o mesmo.

Temos um percentual de $78 \%$ dos professores entrevistados que concorda com o vídeo, afirmando que os professores precisam estar em constante aprendizagem para assim acompanhar a evolução tecnológica que está cada vez mais presente. Por outro lado, foi obtido um percentual de $22 \%$ destes professores que não concordam com o vídeo, acreditando que a TIC não é essencial no auxilio do ensino-aprendizagem. Acredita-se que alguns professores ainda têm a mentalidade que o professor poderá ser deixado de lado se as tecnologias ocuparem o mesmo espaço que deles. Porém Chaves (1998) nos diz:

O uso que o professor vai fazer do computador em sala de aula, atualmente vai depender em parte, de como ele entende esse processo de transformação da sociedade que vem acontecendo, em grande medida em decorrência do desenvolvimento tecnológico, e de como ele se sente em relação a isso, se ele vê todo esse processo como algo benéfico, que pode ajudá-lo na sua vida e no seu trabalho, ou se ele se sente ameaçado e acuado por essas mudanças.

Na questão 9 - quadro1 foi perguntado aos professores quais os recursos tecnológicos e atividades que utilizam em sala de aula para tornar as aulas mais criativas facilitando assim a aprendizagem dos alunos. A partir dos dados obtidos, é possível apontar que $28 \%$ dos professores utilizam o computador, a internet e o rádio como principais mecanismos de ensino e aprendizagem, 25\% utilizam TV/DVD, $10 \%$ utilizam Data Show e por fim, 9\% utilizam outros recursos para tornar as aulas mais criativas.

Os mesmos afirmam ver estas tecnologias como ferramenta para a busca de recursos educacionais como vídeos, figuras, músicas, artigos, mapas, entre outros, visando melhorar sua prática pedagógica e aprendizagem. Com isso, os alunos adquirem novos conhecimentos de maneira mais rápida e prazerosa. Sendo assim: Para Medeiros (2000),

O ambiente de aprendizagem, para que se constitua como tal, cooperativo, autonomizador e interativo pressupõe a presença de diversos atores, entre os quais o professor / equipe e o aluno/ grupo de alunos. O professor faz a mediação com as atividades do aluno, preparando o campo e o ambiente para tal, dispondo e propondo o acesso e a interação, - seja com a máquina ou com outros alunos ou outras tecnologias - provocando e facilitando essas ações.

Também foi perguntado (Questão10-quadro1) se os professores entrevistados possuíam algum curso de capacitação sobre o uso da tecnologia da informação e comunicação como mediador no processo de ensino-aprendizagem. A partir desta questão constatou-se que $78 \%$, a grande maioria dos professores já realizaram algum cursos na área da Informação, cursos como utilização do sistema operacional Linux Educacional, sistema utilizado nos computadores da escola, o que facilita o entendimento sobre a importância da utilização da mesma em sala de aula. Já $22 \%$ afirmaram não ter nenhum curso nesta área o que nos dias atuais é de suma importância. Segundo Penteado (2000) "Professores devem ser parceiros na concepção e condução das atividades com Tecnologias Informáticas e não meros espectadores e executores de tarefas."

Em seguida foi perguntado (questão 11-quadro 1) se o entrevistado utiliza a internet para fazer pesquisas para preparar suas aulas com as opções sim ou não. Todos os entrevistados (100\%) afirmaram que utilizam esse recurso para preparar suas aulas e citam que usam sites de acordo com as suas 
disciplinas.

Para finalizar o questionário (questão 12-quadro 1) foi solicitado aos entrevistados que dessem opiniões quanto à finalidade do uso das tecnologias de informação e comunicação no ensino fundamental. Das expressões emitidas pelos educadores podemos transcrever que o professor deve utilizar todos os meios ou recursos disponíveis para que o aluno possa não só ler e escrever, mas visualizar e ter acesso às informações disponíveis ao seu alcance como é o caso da internet. Os alunos já usam essa ferramenta no seu dia a dia principalmente para interatividade, e deve também utilizá-la como meio de compartilhar saberes.

\section{CONSIDERAÇÕES FINAIS}

O crescimento das tecnologias da informação e comunicação em vários âmbitos profissionais está cada vez mais avançado, provocando mudanças comportamentais, cabendo ao educador criar situações onde o aluno desenvolva criatividade e autonomia possibilitando que o mesmo faça novas descobertas e que o processo de ensino aprendizagem seja mais rápido e inovador tornando a aula mais atraente.

Educar e aprender numa sociedade onde a informação significa muito exige que o professor tenha curiosidade, que ele seja humilde, tolerante, tenha autonomia, consciência e acredite que o uso das tecnologias de informação e comunicação pode desencadear uma nova realidade. Investir na criação de competências amplas permite decisões fundamentais, e operar com fluência tecnológica os novos meios e ferramentas na escola, amplia significativamente o conhecimento. Neste contexto o professor tem papel fundamental de estabelecer vínculos com o aluno, trocar experiências vividas, conteúdos com a ajuda das tecnologias, transformando-os em saberes compartilhados.

Através da investigação realizada com professores e alunos constatou-se que as tecnologias da informação e da comunicação estão sendo utilizadas de maneira a contribuir para a autonomia e aprendizado do aluno na escola, mas ainda existe uma minoria de educados que precisam ser incluidos neste contexto de informação. A escola dispõe de uma estrutura física adequada, porém destaca-se a preocupação de que tal espaço contenha uma equipe capacitada para atender os alunos em suas necessidades. Por outro lado podemos observar que alguns dos alunos possuem uma carência destes recursos (computador e internet) em suas residências, necessitando de uma atenção maior por parte da escola e do professor ensinando e motivando o aluno na escola onde possui as ferramentas.

Diante do exposto concluímos que a utilização das TIC como recurso educacional é de fundamental importância e indispensáveis na educação das crianças e adolescentes. Sendo assim, evidencia-se que cabe a todos que fazem parte da comunidade escolar o aperfeiçoamento e o interesse quanto ao uso das TIC na escola.

\section{REFERÊNCIAS}

ALMEIDA. D.M. Segunda Lei da Termodinâmica, Recursos Digitais e Ensino de Química. 2003. Dissertação de Mestrado, Curso de Pós-graduação em Química para o Ensino, Faculdade de Ciências da Universidade do Porto, Porto, 2003. Disponível em: http://repositorio-aberto.up.pt/handle/10216/14324. Acesso em outubro de 2012.

Atividades de Enriquecimento Curricular - TIC Ler mais. Disponível em: http://aecticmtr.webnode.pt/sobre-as-tic/. Acesso em agosto de 2012.

CHAVES, Eduardo O.C.; SETZER, Valdemar W. O uso de computadores em escolas: Fundamentos e críticas: São Paulo: Scipione, 1988.

DEBALD, Fatima R. B. TICs e Pratica Pedagógica Universitaria.2007. Disponível em:http://www.uniamerica.br/pdf/geral/f11390d4cd.pdf. Acesso em novembro de 2012. 
KENSKI ,Vani Moreira. Tecnologias e ensino presencial e a distância. Campinas: Papirus, 2003.

LÉVY, Pierre. As tecnologias da inteligência: o futuro do pensamento na era da informática. Rio de Janeiro: Ed. 34, 1993.

MEDEIROS, Marilu Fontoura; MEDEIROS, Gilberto; COLLA, Anamaria; Herrelein, Maria Bernadete. A produção de uma ambiente em Educação a Distância com o uso de mídias integradas: a PUCRS VIRTUAL. 2000. Disponível em: http://www.ead.pucrs.br/biblioteca/artigo/Abed_AmbientesAprendizagem.pdf.

Acesso em novembro de 2012.

MORAN, José Manuel; MASETTO, Marcos T.; BEHRENS, Marilda Aparecida. Novas tecnologias e mediação pedagógica. Campinas : Papirus, 2000.

MORAN, J. M. Novas tecnologias e oreencantamento do mundo, 1995. (Especialistaem projeto: inovadores na educação presencial e a distância). Revista Tecnologia Educacional. Rio de Janeiro, 2008. Disponível em http://www.eca.usp.br/prof/moran/nov tec.htm

PENTEADO, Miriam,A Informática em ação - Formação de professores, pesquisa e extensão - Editora Olho d'Água, 2000. 